\title{
DPYD Negative
}

National Cancer Institute

\section{Source}

National Cancer Institute. DPYD Negative. NCI Thesaurus. Code C150498.

An indication that expression of DPYD has not been detected in a sample. 